Article

\title{
Comparison of Copper Scavenging Capacity between Two Different Red Mud Types
}

\author{
Yingqun Ma ${ }^{1,3}$, Chunhua $\mathrm{Si}^{1}$ and Chuxia $\operatorname{Lin}^{2, *}$
}

1 Centre for Ecological and Environmental Technologies, South China Agricultural University, Guangzhou 510642, China; E-Mails: myoungking@163.com (Y.M.); siqisxnd@yahoo.com.cn (C.S.)

2 Australian Centre for Sustainable Catchments, University of Southern Queensland, Toowoomba QLD 4350, Australia

3 Chinese Research Academy of Environmental Sciences, Beijing 100012, China

* Author to whom correspondence should be addressed; E-Mail: Chuxia.Lin@usq.edu.au; Tel.: +61-7-463-124-29; Fax: +61-7-463-155-81.

Received: 27 July 2012; in revised form: 28 August 2012 / Accepted: 3 September 2012 / Published: 24 September 2012

\begin{abstract}
A batch experiment was conducted to compare the $\mathrm{Cu}$ scavenging capacity between two different red mud types: the first one was a highly basic red mud derived from a combined sintering and Bayer process, and the second one was a seawater-neutralized red mud derived from the Bayer process. The first red mud contained substantial amounts of $\mathrm{CaCO}_{3}$, which, in combination with the high $\mathrm{OH}^{-}$activity, favored the immobilization of water-borne $\mathrm{Cu}$ through massive formation of atacamite. In comparison, the seawater-neutralized red mud had a lower $\mathrm{pH}$ and was dominated by boehmite, which was likely to play a significant role in $\mathrm{Cu}$ adsorption. Overall, it appears that $\mathrm{Cu}$ was more tightly retained by the $\mathrm{CaCO}_{3}$-dominated red mud than the boehmite-dominated red mud. It is concluded that the heterogeneity of red mud has marked influences on its capacity to immobilize water-borne $\mathrm{Cu}$ and maintain the long-term stability of the immobilized $\mathrm{Cu}$ species. The research findings obtained from this study have implications for the development of $\mathrm{Cu}$ immobilization technology by using appropriate waste materials generated from the aluminium industry.
\end{abstract}

Keywords: alumina; bauxite; red mud; calcite; alkaline; copper; boehmite; atacamite; metal immobilization 


\section{Introduction}

As an abundant waste material generated from alumina refining, beneficial utilization of red mud is a viable option to reduce the amount of this hazardous material that requires costly containment facilities for its safe disposal [1-11]. The uses of red mud or modified red mud for treating acidic, heavy metal-bearing soils and wastewater are among the proposed applications [12-24].

In a previous study [22] to investigate the competitive removal of water-borne $\mathrm{Cu}, \mathrm{Zn}$ and $\mathrm{Cd}$ by a red mud sample collected from the Zhengzhou Alumina Refinery, we found that the water-borne $\mathrm{Cu}$ had a higher affinity to the red mud in the presence of chloride, as compared to the water-borne $\mathrm{Zn}$ and $\mathrm{Cd}$. The major mechanism responsible for the preferential retention of $\mathrm{Cu}$ by the red mud was the formation of atacamite $\left(\mathrm{Cu}_{2}(\mathrm{OH})_{3} \mathrm{Cl}\right)$, which maximized the $\mathrm{Cu}$ scavenging effect.

Red mud is a heterogeneous material and its characteristics varies markedly from place to place, depending on the sources of bauxite ores, alumina refining processes and the methods used for red mud disposal $[25,26]$. Consequently, the capacity of red mud to scavenge $\mathrm{Cu}$ may also vary from red mud type to red mud type. In the current study, two significantly different red mud types were used to test their capacities to remove water-borne $\mathrm{Cu}$. Fractionation of the retained $\mathrm{Cu}$ was also investigated. The objective was to understand the influences of red mud heterogeneity on its performance as a $\mathrm{Cu}$ scavenger under the set experimental conditions.

\section{Materials and Methods}

\subsection{The Red Mud Samples}

Two different red mud types were used for the experiment. The first one (labeled as GR) was collected from the Guizhou Alumina Refinery at Guiyang, China and the second one (Labeled as QR) was collected from the Queensland Alumina Refinery at Gladstone, Australia. The Guizhou Alumina Refinery used diaspore-dominated bauxite ore as the feedstock [27]. A combined sintering process and Bayer Process method was used for bauxite processing and the red mud was disposed of using a wet disposal method. The Queensland Alumina Refinery used a Bayer Process method for alumina extraction from gibbsite-boehmite type bauxite ore mined from Weipa, northern Queensland [28]. The red mud was treated by seawater before being thickened and deposited as slurry in the disposal facility.

Surface red mud samples were collected from the red mud storage facilities of the above two refineries. In the laboratory, the red mud samples were air-dried and ground to pass through a 60 mesh sieve $(250 \mu \mathrm{m})$. Some chemical characteristics of the two red mud samples are given in Table 1.

\subsection{Copper Scavenging Experiment}

The experiment was performed in triplicate. For each red mud type, 25 grams of the red mud sample were reacted with a series of $\mathrm{CuCl}_{2}$ solutions with varying concentrations. A total of eight $\mathrm{Cu}$ concentration levels were originally set for the experiment: 3437.5, 6875, 13,750, 27,500, 34,375, $41,250,48,125$ and $61,875 \mathrm{mg} / \mathrm{L}$. Pre-experiment test showed that the QR was not able to remove all water-borne $\mathrm{Cu}$ at a dosage level of $27,500 \mathrm{mg} / \mathrm{L}$. Therefore, only five $\mathrm{Cu}$ concentration levels were performed for the QR: 3437.5, 6875, 13,750, 27,500, 34,375 $\mathrm{mg} / \mathrm{L}$. The red mud sample was mixed 
with $100 \mathrm{~mL}$ of a relevant solution in a stoppered conical flask $(150 \mathrm{~mL})$ and shaken on a HY-4 horizontal shaker for $16 \mathrm{~h}$. The suspension was then transferred to a centrifuge tube for centrifugation at $4000 \mathrm{rpm}$ for $10 \mathrm{~min}$. After separation, the supernatant was used for determination of soluble $\mathrm{Cu}, \mathrm{Ca}$ and $\mathrm{Fe}$. The solid residue was used for various chemical and mineralogical analyses after washing with deionized water twice and air-drying.

Table 1. Some major chemical and mineralogical parameters of the two red mud types used in the experiment.

\begin{tabular}{lcc}
\hline \multicolumn{1}{c}{ Parameter } & Guizhou red mud & Queensland red mud \\
\hline pH & 11.0 & 9.4 \\
EC (dS/m) & 0.89 & 1.26 \\
Total carbon (\%) & 4.13 & 1.05 \\
Total Ca (mg/kg) & 183,800 & 61,900 \\
Total Cu (mg/kg) & 85 & 145 \\
Soluble K (mmol/kg) & 6.24 & 16.9 \\
Soluble Na (mmol/kg) & 70.2 & 71.9 \\
Soluble Ca (mmol/kg) & 1.19 & 0.36 \\
Soluble Mg (mmol/kg) & 0.06 & 0.11 \\
Exchangeable K (mmol/kg) & 83.7 & 74.0 \\
Exchangeable Na (mmol/kg) & 218 & 236 \\
Exchangeable Ca (mmol/kg) & 341 & 23.7 \\
Exchangeable Mg (mmol/kg) & 4.01 & 4.16 \\
Major minerals & calcite, perovskite, & boehmite, quartz, larnite, calcite, magnetite, \\
& monohydrocalcite, magnetite & perovskite, gibbsite, sodalite, anatase \\
\hline
\end{tabular}

\subsection{Analytical Methods}

Various fractions of $\mathrm{Cu}$ in the solid samples were extracted by different extractants. 1:5 (red mud:deionized water) and 1:5 (red mud: $1 \mathrm{M} \mathrm{NH}_{4} \mathrm{Cl}$ ) extracts were prepared for determinations of the water-extractable and the $1 \mathrm{M} \mathrm{NH}_{4} \mathrm{Cl}$-extractable $\mathrm{Cu}$. The water-extractable fraction was used to estimate the concentration of the water-soluble $\mathrm{Cu}$ fraction. The $1 \mathrm{M} \mathrm{NH}_{4} \mathrm{Cl}$-extractable fraction includes water-soluble and exchangeable $\mathrm{Cu}$. The improved BCR sequential extraction procedure [29] was used to separate the following three $\mathrm{Cu}$ fractions in the solid residues: (a) $0.11 \mathrm{M} \mathrm{HCH}_{3} \mathrm{COO}$-extractable $\mathrm{Cu}$ (termed as Fraction I), (b) $0.5 \mathrm{M} \mathrm{NH} \mathrm{N}_{2} \mathrm{OH} \cdot \mathrm{HCl}$-extractable $\mathrm{Cu}$ (termed as Fraction II) and (c) $1 \mathrm{M}$ $\mathrm{NH}_{2} \mathrm{CH}_{3} \mathrm{COOH}$-extractable $\mathrm{Cu}$ after $30 \% \mathrm{H}_{2} \mathrm{O}_{2}$ digestion (termed as Fraction III). In the BCR system, Fraction I was thought to include water-soluble, adsorbed and carbonate-bound metal; Fraction II was viewed to be in the forms bound to oxides of iron and manganese; and Fraction III was believed to include a metal bound to organic matter and sulfide minerals. The BCR sequential extraction procedure was designed for fractionation of heavy metals in soils and sediments. It was adopted for this study because no verified sequential extraction methods for red mud materials were available. However, it was realized that the operationally defined fractions of heavy metals obtained from the BCR sequential extraction procedure may require new interpretation when the method was used for heavy metal fractionation of red mud, which is somewhat different from soils or sediments in terms of 
physico-chemical properties and composition. Total $\mathrm{Cu}$ were extracted by digestion of a sample with a $\mathrm{HF} / \mathrm{HNO}_{3} / \mathrm{HClO}_{4}$ mixed solution.

The concentrations of $\mathrm{Cu}, \mathrm{Ca}$ and $\mathrm{Fe}$ in the supernatants and various extracts of the solid residues were determined by atomic absorption spectrometry (AAS). Carbon concentration of the solid residues was measured by a LECO CNS Analyzer. Mineral composition was determined using a Bruker D8 ADVANCE X-ray diffractometer. The Materials Data Inc. software Jade 5.0 was used for phase identification. Semi-quantitative phase analysis was performed using the computer program PCPDFWIN (I/Icor reference intensity ratio method). The samples were also used for examination of micro-morphological characteristics by A FEI-XL30 environmental scanning electron microscope coupled with energy dispersive X-ray spectrometer (ESEM/EDS).

\subsection{Statistical Method}

The data for the replicated experiment are presented as mean $\pm \mathrm{SD}$. The significant treatment differences were tested using a Duncan's multiple range test method.

\section{Results}

\subsection{Concentrations of $\mathrm{Cu}, \mathrm{Fe}$ and $\mathrm{Ca}$ in the Solutions after $16 \mathrm{~h}$ Reaction}

After shaking of the red mud- $\mathrm{CuCl}_{2}$ solution mixtures for $16 \mathrm{~h}$, almost all the added $\mathrm{Cu}$ was removed from the solution for the Guizhou red mud (GR). The highest dose of $\mathrm{Cu}$ in this experiment was $61,875 \mathrm{mg} / \mathrm{L}$, indicating that GR had a Cu scavenging capacity greater than $247 \mathrm{~g} / \mathrm{kg}$. In comparison, greater than 7\% and 19\% of the added $\mathrm{Cu}$ remained in the solution for the Queensland red mud (QR) when the initial concentration of solution $\mathrm{Cu}$ was 27,500 and $34,375 \mathrm{mg} / \mathrm{L}$, respectively (Table 2).

Table 2. Concentrations of $\mathrm{Cu}, \mathrm{Fe}$ and $\mathrm{Ca}$ in the reacting solutions after $16 \mathrm{~h}$ reaction for the two red mud types.

\begin{tabular}{lcccc}
\hline Red mud type & OCCRS (mg/L) & Cu (mg/L) & Fe (mg/L) & Ca (mg/L) \\
\hline GR & 3437.5 & $0.05 \pm 0.01 \mathrm{a}$ & $0.04 \pm 0.00 \mathrm{ab}$ & $935.6 \pm 21.17 \mathrm{a}$ \\
& 6875 & $0.04 \pm 0.00 \mathrm{a}$ & $0.03 \pm 0.01 \mathrm{a}$ & $2294 \pm 268.1 \mathrm{~b}$ \\
13,750 & $0.07 \pm 0.07 \mathrm{a}$ & $0.04 \pm 0.01 \mathrm{ab}$ & $5623 \pm 133.2 \mathrm{c}$ \\
27,500 & $0.05 \pm 0.01 \mathrm{a}$ & $0.04 \pm 0.01 \mathrm{ab}$ & $11,482 \pm 256.70 \mathrm{~d}$ \\
& 34,375 & $0.30 \pm 0.37 \mathrm{a}$ & $0.49 \pm 0.01 \mathrm{ab}$ & $14,128 \pm 41.36 \mathrm{e}$ \\
41,250 & $0.11 \pm 0.02 \mathrm{a}$ & $0.05 \pm 0.00 \mathrm{ab}$ & $17,274 \pm 267.1 \mathrm{f}$ \\
48,125 & $0.13 \pm 0.02 \mathrm{a}$ & $0.05 \pm 0.01 \mathrm{ab}$ & $19,520 \pm 476.9 \mathrm{~g}$ \\
& 61,875 & $0.12 \pm 0.01 \mathrm{a}$ & $0.08 \pm 0.06 \mathrm{~b}$ & $27,407 \pm 598.2 \mathrm{~h}$ \\
QR & $1.46 \pm 0.19 \mathrm{a}$ & $0.04 \pm 0.00 \mathrm{a}$ & $536.2 \pm 15.31 \mathrm{a}$ \\
& 6837.5 & $1.40 \pm 0.68 \mathrm{a}$ & $0.05 \pm 0.02 \mathrm{a}$ & $1281 \pm 194.5 \mathrm{~b}$ \\
& 13,750 & $2.23 \pm 0.29 \mathrm{a}$ & $0.05 \pm 0.00 \mathrm{a}$ & $3484 \pm 22.45 \mathrm{c}$ \\
& 27,500 & $1988 \pm 168.1 \mathrm{~b}$ & $0.12 \pm 0.07 \mathrm{~b}$ & $5593 \pm 361.7 \mathrm{~d}$ \\
& 34,375 & $6748 \pm 182.0 \mathrm{c}$ & $0.10 \pm 0.02 \mathrm{~b}$ & $5781 \pm 190.1 \mathrm{~d}$ \\
\hline
\end{tabular}

Notes: OCCRS: Original $\mathrm{Cu}$ concentration in the reacting solution; Means with different letters in the same column differ significantly at $\mathrm{P}<0.05$. 
With the increase in $\mathrm{Cu}$ dose, the concentration of $\mathrm{Ca}$ in the solution increased for both red mud types. This was consistent with what was observed in our previous study [22]. However, Ca concentration was always higher in GR than in QR at the same $\mathrm{Cu}$ dose level (Table 2).

At any dose of $\mathrm{CuCl}_{2}$, only trace amounts of $\mathrm{Fe}$ was detected in the solutions of either $\mathrm{GR}$ or QR after $16 \mathrm{~h}$ reaction (Table 2 ).

\subsection{Total Retained Cu and Total Carbon in the Solid Residues}

Change in the total retained $\mathrm{Cu}$ with the increase in $\mathrm{CuCl}_{2}$ dose for the two red mud types is shown in Figure 1a. For $\mathrm{GR}$, the total retained $\mathrm{Cu}$ increased nearly linearly with increasing dose for the examined range of $\mathrm{CuCl}_{2}$ concentrations. Initially, the dose-response relationship for QR was highly consistent with that for GR. However, a gap was created at least before a $\mathrm{Cu}$ dose of $27,500 \mathrm{mg} / \mathrm{L}$ was reached; $\mathrm{QR}$ had a lower total retained $\mathrm{Cu}$ value than did GR. There was no marked change in the total retained $\mathrm{Cu}$ between the $\mathrm{Cu}$ dose of $27,500 \mathrm{mg} / \mathrm{L}$ and $34,375 \mathrm{mg} / \mathrm{L}$.

Figure 1. Diagrams showing the change in (a) the total retained $\mathrm{Cu}$ and (b) the total carbon in the solid residues with increasing dose of $\mathrm{CuCl}_{2}$ for the two tested red mud types.
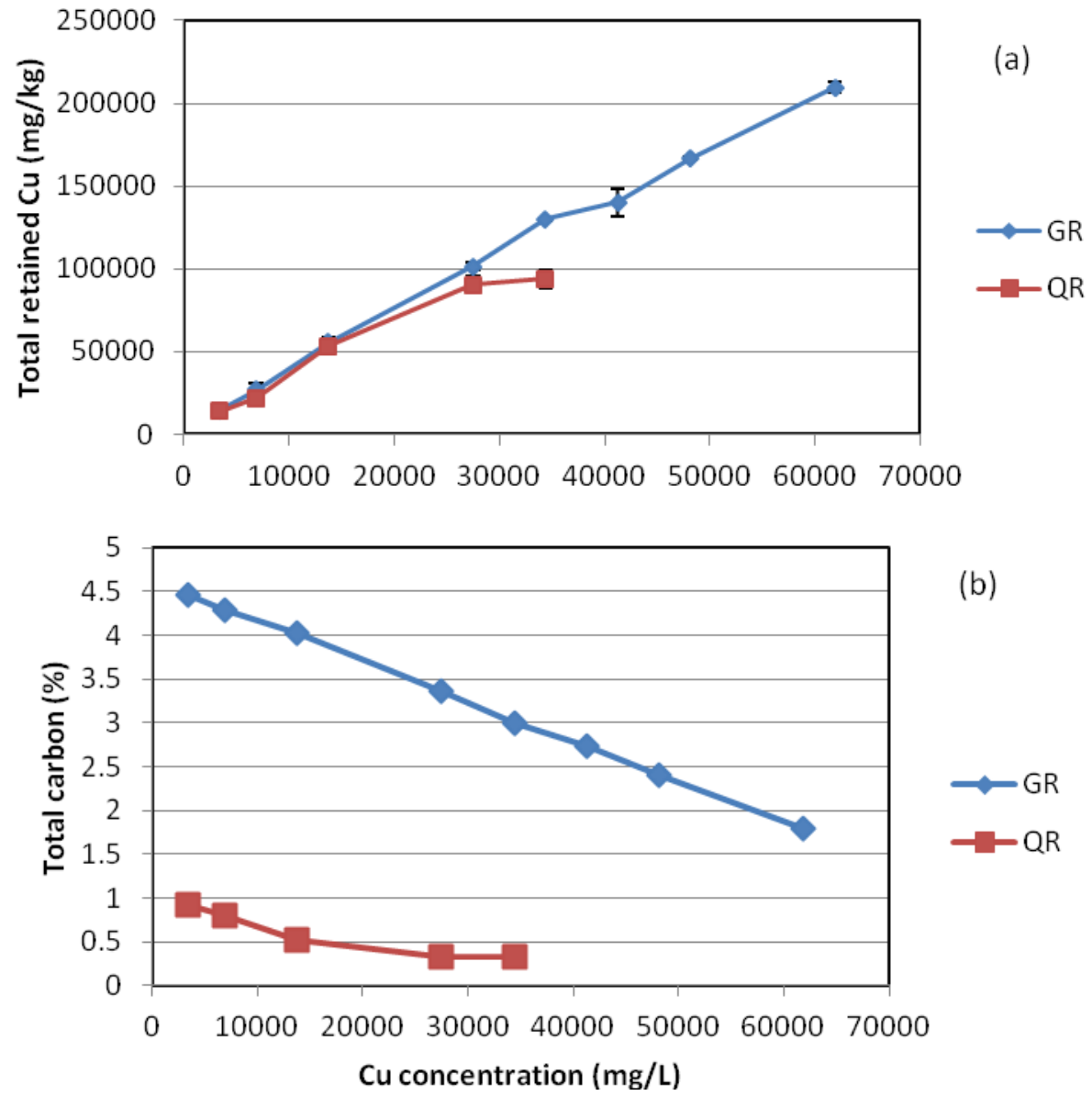

The change in the total carbon content in the solid residues with increasing $\mathrm{Cu}$ dose showed an opposite trend to that of the total retained $\mathrm{Cu}$. Similarly, a nearly linear dose-response relationship was observed for GR while QR exhibited a relatively rapid, gentle and insignificant change in the dose ranges of $3437.5-13,750,13,750-27,500$ and $27,500-34,375 \mathrm{mg} / \mathrm{L}$, respectively (Figure $1 \mathrm{~b}$ ). 


\section{3. $\mathrm{pH}, \mathrm{EC}$, Water-Extractable and $\mathrm{NH}_{4} \mathrm{Cl}$-Extractable $\mathrm{Cu}$ of the Solid Residues}

There was a trend that $\mathrm{pH}$ decreased and $\mathrm{EC}$ increased with increasing dose of $\mathrm{CuCl}_{2}$ for both red mud types. For GR, the mean $\mathrm{pH}$ decreased from 9.12 to 7.60 with the increase in $\mathrm{Cu}$ dose from 3437.5 to $61,875 \mathrm{mg} / \mathrm{L}$. For QR, the $\mathrm{pH}$ was below 5 at a $\mathrm{Cu}$ dose greater than 27,500 mg/L (Table 3).

Table 3. $\mathrm{pH}, \mathrm{EC}$, water-extractable and $\mathrm{NH}_{4} \mathrm{Cl}$-extractable $\mathrm{Cu}$ in the solid residues after $16 \mathrm{~h}$ reaction.

\begin{tabular}{|c|c|c|c|c|c|}
\hline Red mud type & OCCRS (mg/L) & pH & EC (dS/m) & $\mathrm{Cu}_{\mathrm{w}}(\mathrm{mg} / \mathrm{kg})$ & $\mathrm{Cu}_{\mathrm{am}}(\mathrm{mg} / \mathrm{kg})$ \\
\hline \multirow[t]{8}{*}{ GR } & 3437.5 & $9.12 \pm 0.02 \mathrm{e}$ & $0.198 \pm 0.003 b c$ & $0.23 \pm 0.10 \mathrm{ab}$ & $275 \pm 28.2 d$ \\
\hline & 6875 & $8.79 \pm 0.04 d$ & $0.189 \pm 0.008 b$ & $0.14 \pm 0.05 \mathrm{ab}$ & $286 \pm 7.97 \mathrm{~d}$ \\
\hline & 13,750 & $8.46 \pm 0.07 c$ & $0.174 \pm 0.003 \mathrm{a}$ & $0.50 \pm 0.08 \mathrm{c}$ & $145 \pm 13.4 \mathrm{c}$ \\
\hline & 27,500 & $8.00 \pm 0.05 b$ & $0.204 \pm 0.009 c$ & $0.27 \pm 0.15 \mathrm{ab}$ & $91.3 \pm 4.55 b$ \\
\hline & 34,375 & $7.91 \pm 0.06 b$ & $0.222 \pm 0.006 \mathrm{~d}$ & $0.09 \pm 0.07 \mathrm{a}$ & $81.7 \pm 8.53 b$ \\
\hline & 41,250 & $8.00 \pm 0.20 b$ & $0.222 \pm 0.005 \mathrm{~d}$ & $0.09 \pm 0.02 \mathrm{a}$ & $85.9 \pm 7.37 b$ \\
\hline & 48,125 & $7.73 \pm 0.16 a$ & $0.233 \pm 0.008 \mathrm{e}$ & $0.27 \pm 0.19 \mathrm{ab}$ & $71.6 \pm 1.26 \mathrm{ab}$ \\
\hline & 61,875 & $7.60 \pm 0.03 a$ & $0.286 \pm 0.001 \mathrm{f}$ & $0.33 \pm 0.16 b c$ & $55.0 \pm 4.32 \mathrm{a}$ \\
\hline \multirow[t]{5}{*}{ QR } & 3437.5 & $7.99 \pm 0.03 d$ & $0.214 \pm 0.003 a$ & $0.02 \pm 0.02 \mathrm{a}$ & $198 \pm 12.66 d$ \\
\hline & 6875 & $7.95 \pm 0.01 \mathrm{~d}$ & $0.215 \pm 0.003 a$ & $0.04 \pm 0.02 \mathrm{a}$ & $181 \pm 1.87 \mathrm{c}$ \\
\hline & 13,750 & $7.66 \pm 0.06 c$ & $0.228 \pm 0.005 b$ & $0.04 \pm 0.02 \mathrm{a}$ & $92.5 \pm 9.10 \mathrm{a}$ \\
\hline & 27,500 & $4.82 \pm 0.19 b$ & $0.253 \pm 0.012 c$ & $51.9 \pm 3.41 b$ & $108 \pm 3.06 \mathrm{~b}$ \\
\hline & 34,375 & $4.64 \pm 0.04 \mathrm{a}$ & $0.358 \pm 0.001 \mathrm{~d}$ & $186 \pm 5.22 \mathrm{c}$ & $196 \pm 5.13 \mathrm{ab}$ \\
\hline
\end{tabular}

Notes: OCCRS: original $\mathrm{Cu}$ concentration in the reacting solution; $\mathrm{Cu}_{\mathrm{w}}$ : water-extractable $\mathrm{Cu}$; $\mathrm{Cu}_{\mathrm{am}}$ : $\mathrm{NH}_{4} \mathrm{Cl}$-extractable $\mathrm{Cu}$; Means with different letters in the same column differ significantly at $\mathrm{P}<0.05$.

For $\mathrm{GR}$, the water-extractable $\mathrm{Cu}\left(\mathrm{Cu}_{\mathrm{w}}\right)$ was all very low regardless of the dosage level of $\mathrm{CuCl}_{2}$. In contrast, $\mathrm{Cu}_{\mathrm{w}}$ in $\mathrm{QR}$ was $>50 \mathrm{mg} / \mathrm{kg}$ at a $\mathrm{Cu}$ dose greater than $27,500 \mathrm{mg} / \mathrm{L}$. Extraction by ammonium chloride enhanced the release of the retained $\mathrm{Cu}$. This was particularly true for the treatments with lower doses of $\mathrm{CuCl}_{2}$ (Table 3 ).

\subsection{Ca- and Cu-Bearing Minerals in the Solid Residues}

For GR, the abundance of atacamite showed no marked increase in the $\mathrm{Cu}$ dose range of $3437.5-13,750 \mathrm{mg} / \mathrm{L}$; an increase in atacamite occurred when the $\mathrm{Cu}$ dose was increased to $27,500 \mathrm{mg} / \mathrm{L}$; the abundance of atacamite sharply increased from the $\mathrm{Cu}$ dose of $27,500 \mathrm{mg} / \mathrm{L}$ to the $\mathrm{Cu}$ dose of $41,250 \mathrm{mg} / \mathrm{L}$, followed by a relatively gentler increase in the $\mathrm{Cu}$ dose range of 41,250-61,875 $\mathrm{mg} / \mathrm{L}$. This dose-response trend was accompanied by an opposite dose-response trend of calcite. In contrast with calcite, perovskite displayed no marked change despite that a general trend showing slight decrease in the abundance of perovskite with increasing $\mathrm{Cu}$ dose was observed (Figure 2a).

No perovskite was detected for QR. Similar to GR, change in either atacamite or calcite was not remarkable in the low $\mathrm{Cu}$ dose range. The abundance of atacamite markedly increased, accompanied by a marked decrease in calcite when the $\mathrm{Cu}$ dose was increased from $6875 \mathrm{mg} / \mathrm{L}$ to $13,750 \mathrm{mg} / \mathrm{L}$. After this, atacamite increased slowly with increasing $\mathrm{Cu}$ dose. Calcite was not detected in the high $\mathrm{Cu}$ dose range $(13,750-34,375 \mathrm{mg} / \mathrm{L})$. 
Figure 2. Changes in the abundance of $\mathrm{Ca}$ - and $\mathrm{Cu}$-bearing minerals with increasing $\mathrm{Cu}$ dose for (a) GR and (b) QR.
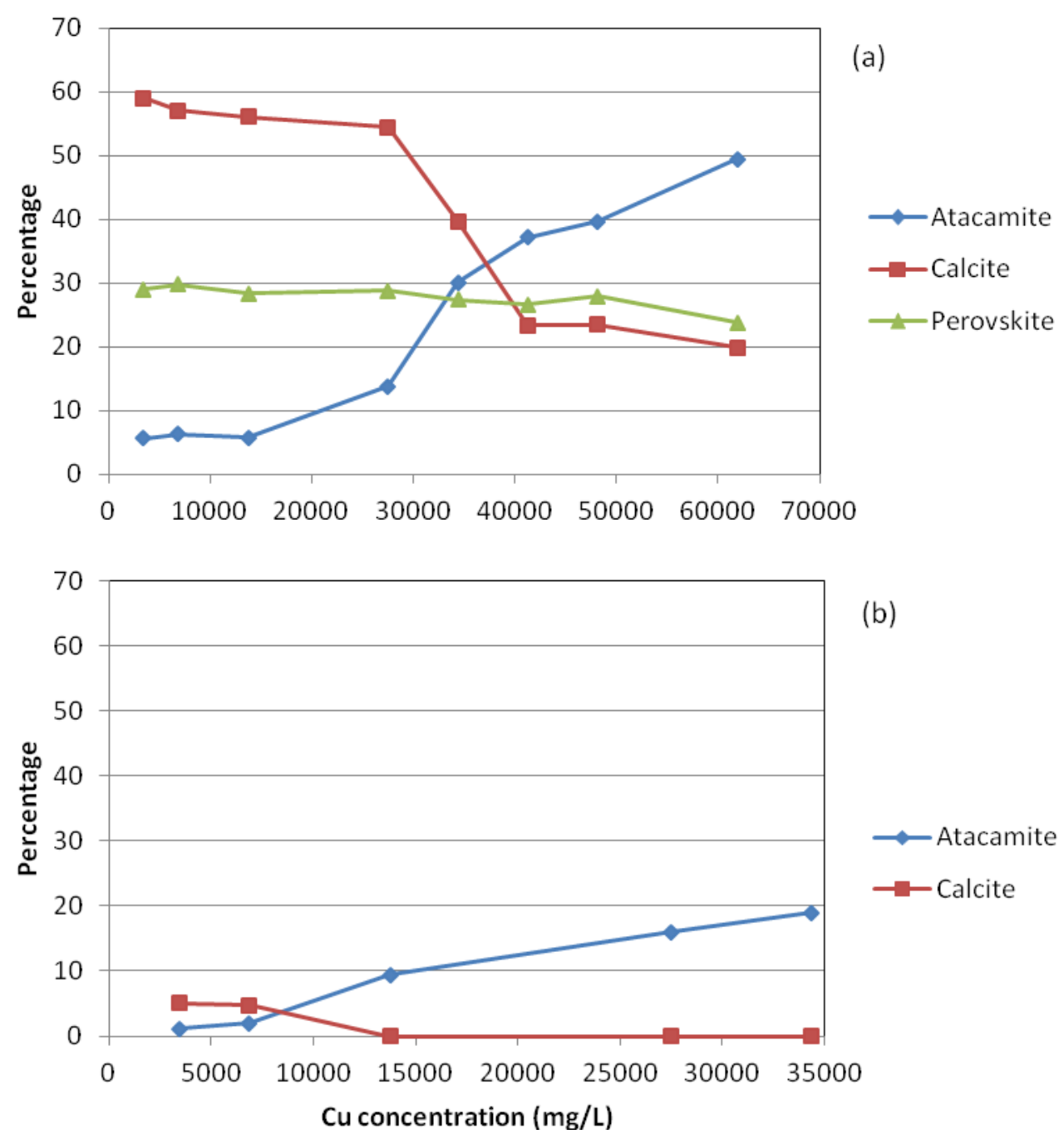

\subsection{Cu Fractionation}

The distribution of three operationally defined $\mathrm{Cu}$ fractions was different between the two red mud types. The order of various $\mathrm{Cu}$ fractions was: Fraction II $>$ Fraction I > Fraction III for GR and Fraction I > Fraction II > Fraction III for QR (Figure 3). For individual fractions, Fraction I was higher in QR than in GR; Fraction II was much higher in GR than in QR; and Fraction III was slightly higher in GR than in QR.

\subsection{SEM Observation and EDS Analysis}

The original GR and QR consisted predominantly of densely packed aggregates (Figure 4a and 4e). Reaction with $\mathrm{CuCl}_{2}$ resulted in the formation of loose aggregates (Figure $4 \mathrm{~b}$ and $4 \mathrm{f}$ ), and the abundance and size of such loose aggregates tended to increase with increasing $\mathrm{Cu}$ dose (Figure $4 \mathrm{c}$ ).

There were some blue precipitates on the wall of the conical flask for GR at high $\mathrm{Cu}$ doses. These precipitates appeared as loose, rough and irregular aggregates of varying sizes (Figure 4d). EDS 
analysis showed that these materials had markedly elevated concentration of $\mathrm{Cu}$ and $\mathrm{Cl}$ and reduced concentration of $\mathrm{Ca}$ (Figure 5a), as compared to the original GR (Figure 5b).

Figure 3. Comparison of the variation trend of various $\mathrm{Cu}$ fractions between $\mathrm{GR}$ and $\mathrm{QR}$ : (a) Fraction I; (b) Fraction II; (c) Fraction III.

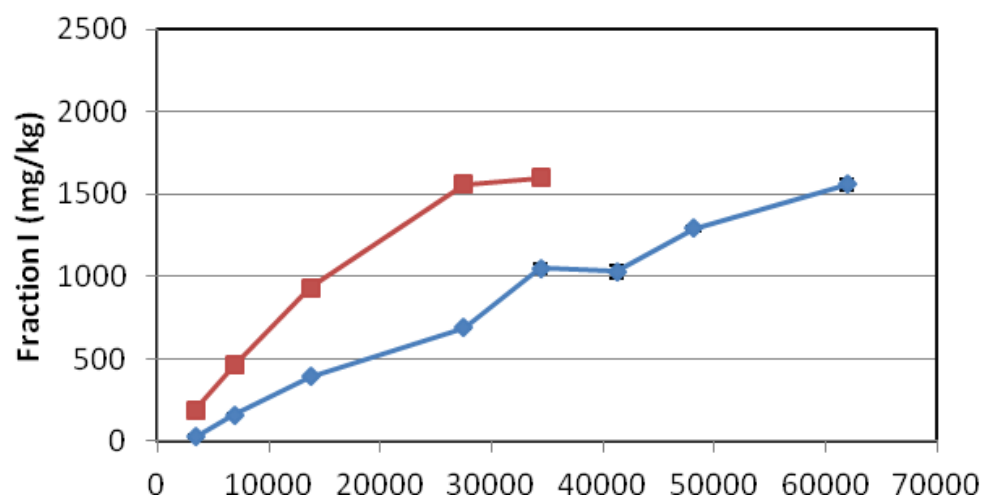

(a)

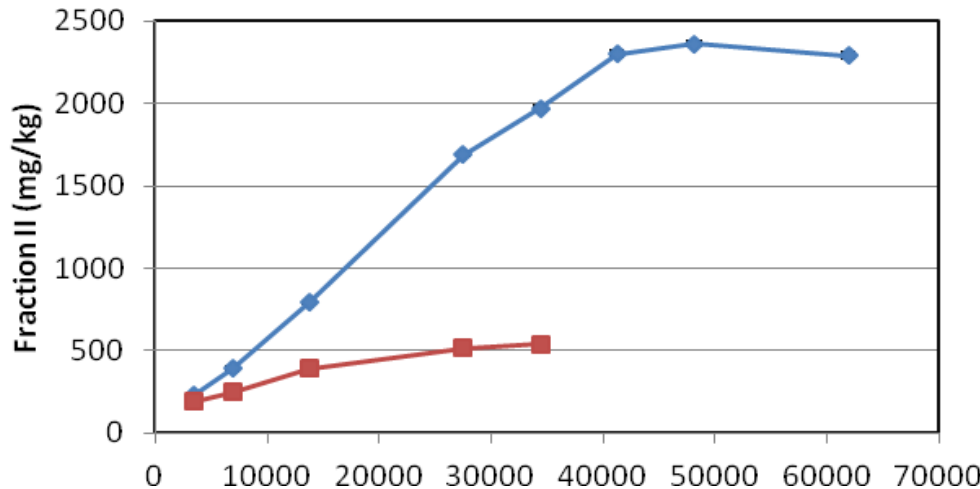

(b)

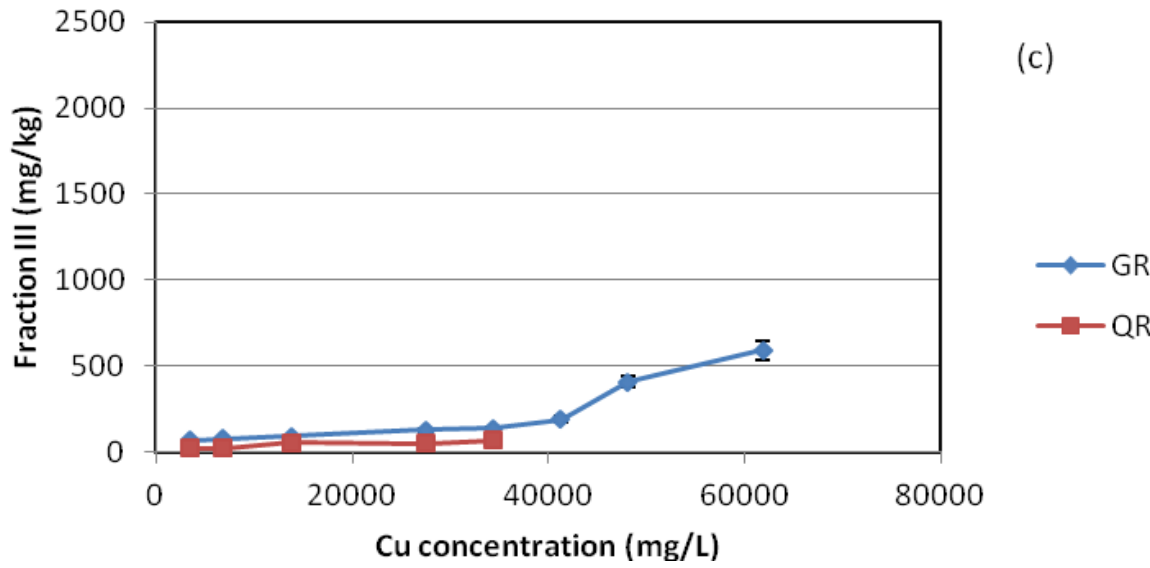


Figure 4. SEM images showing micro-morphological characteristics of (a) original GR; (b) GR at a Cu dose of 27,500 mg/L; (c) GR at a Cu dose of $61,875 \mathrm{mg} / \mathrm{L}$; (d) blue precipitates for GR at a Cu dose of 61,875 mg/L; (e) original QR; (f) QR at a Cu dose of 34,375 mg/L.
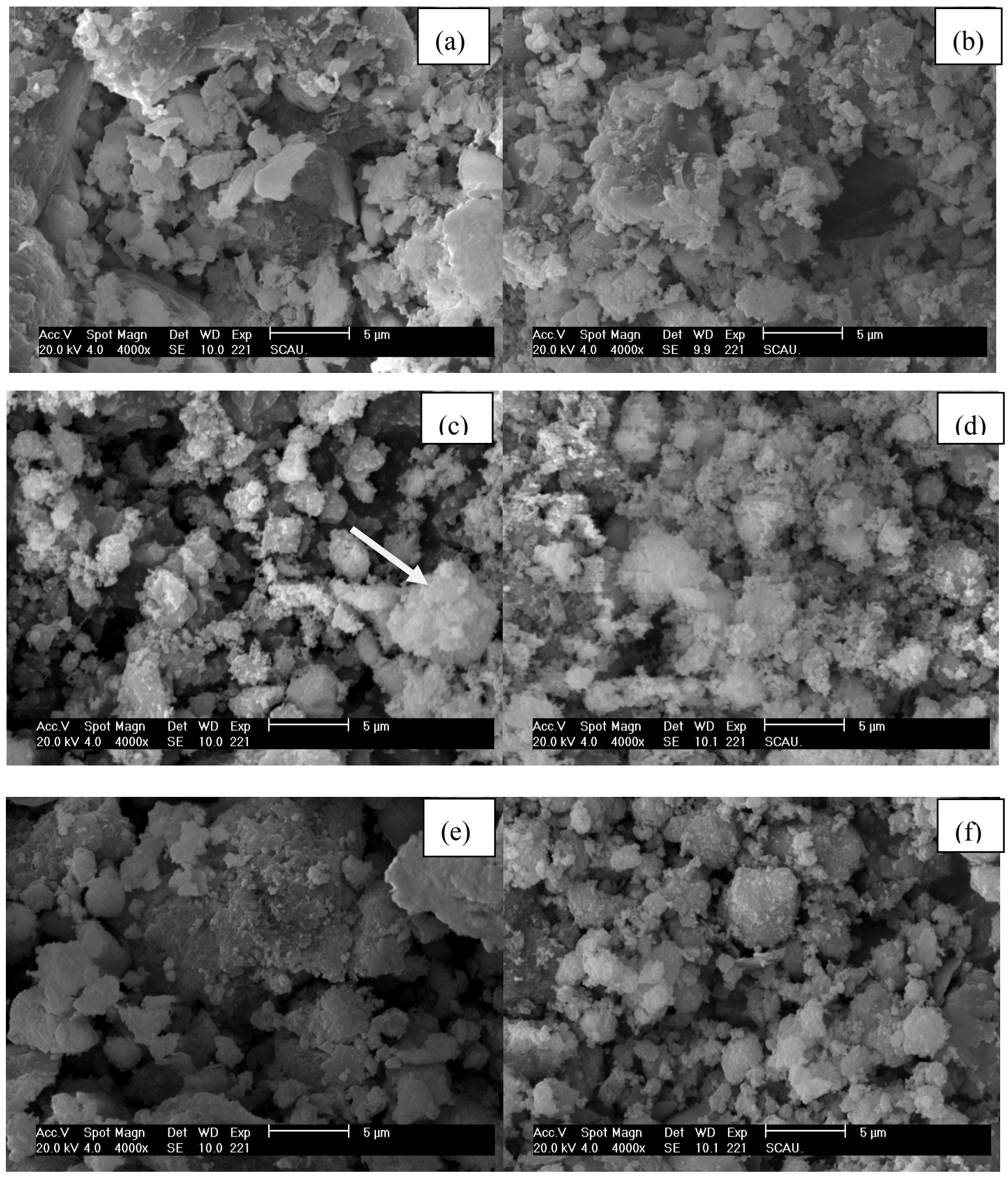
Figure 5. EDS graphs showing peaks of major elements detected for (a) blue precipitates (at $\mathrm{Cu}$ dose of $61,875 \mathrm{mg} / \mathrm{L}$ ) and (b) the original GR sample.
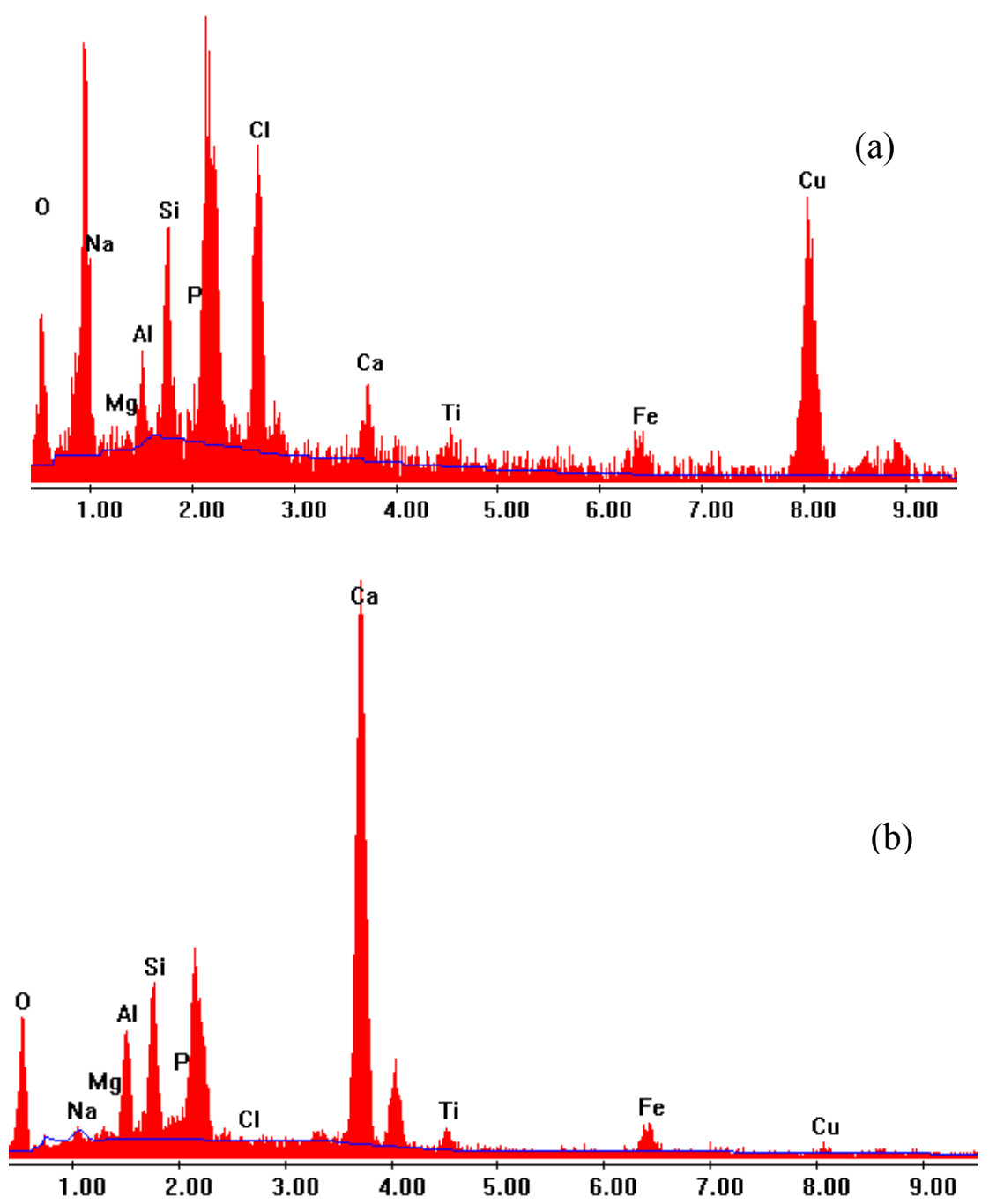

\section{Discussion}

The two red mud types investigated in this study were remarkably different in terms of chemical and mineralogical characteristics. GR was a $\mathrm{CaCO}_{3}$-dominated, highly basic red mud while QR was a boehmite-dominated and less basic red mud. Due to the presence of substantial amounts of $\mathrm{NaOH}$ in GR, the initial formation of atacamite was likely to be through the following reaction [22]:

$$
2 \mathrm{CuCl}_{2}+3 \mathrm{NaOH} \rightarrow \mathrm{Cu}_{2}(\mathrm{OH})_{3} \mathrm{Cl}+3 \mathrm{NaCl}
$$

The above reaction did not involve dissolution of calcite. This explains why the carbon content in the soil residue did not decrease in the lower $\mathrm{Cu}$ dose range $(3437.5-6875 \mathrm{mg} / \mathrm{L})$. The even higher carbon content in the solid residues, as compared to that in the original red mud, can be attributed to the mass loss of the solid material as a result of dissolution of the soluble constitutes when they were in contact with the $\mathrm{CuCl}_{2}$ solution. This is further confirmed by the fact that the $\mathrm{pH}$ of these two solid residues had a $\mathrm{pH}>8.7$, indicating that there was still free $\mathrm{OH}^{-}$in the solid residues. Dissolution of calcite at a $\mathrm{pH}>8.3$ was kinetically slow [30]. Therefore, reaction in Equation (2) was unlikely to take 
place to any significant degree. With the increase in the $\mathrm{Cu}$ dose, $\mathrm{OH}^{-}$was eventually depleted and $\mathrm{CaCO}_{3}$ replace $\mathrm{OH}^{-}$to react with $\mathrm{CuCl}_{2}$, as expressed below:

$$
2 \mathrm{CuCl}_{2}+2 \mathrm{CaCO}_{3}+2 \mathrm{H}_{2} \mathrm{O} \rightarrow \mathrm{Cu}_{2}(\mathrm{OH})_{3} \mathrm{Cl}+3 \mathrm{Cl}^{-}+\mathrm{OH}^{-}+2 \mathrm{Ca}^{2+}+\mathrm{CO}_{2}
$$

This was well reflected in the scenarios of high $\mathrm{Cu}$ doses, showing lower carbon content in the solid residue, relative to that in the original red mud and a clear trend that carbon content in the solid residue decreased with increasing $\mathrm{Cu}$ dose (Figure $1 \mathrm{~b}$ ).

In contrast, the carbon content in the solid residue was lower than that in the original red mud for $\mathrm{QR}$ even at the lowest $\mathrm{Cu}$ dose $(3437.5 \mathrm{mg} / \mathrm{L})$. Since the amount of free $\mathrm{OH}^{-}$in $\mathrm{QR}$ was very limited, reaction in Equation (2) took place immediately following the mixing of red mud with $\mathrm{CuCl}_{2}$. It is clear that the $\mathrm{Cu}$-scavenging capacity of $\mathrm{QR}$ was almost depleted at a $\mathrm{Cu}$ dose of $27,500 \mathrm{mg} / \mathrm{L}$. This can be attributed to the small amount of $\mathrm{CaCO}_{3}$ present in $\mathrm{QR}$.

The difference in the distribution of the three $\mathrm{Cu}$ fractions suggests that the mineral composition of red mud had a marked influence on the binding form of $\mathrm{Cu}$. The boehmite-dominated $\mathrm{QR}$ tended to have stronger capacity to hold $\mathrm{Cu}$ in the form of Fraction I, which consists of soluble, adsorbed and carbonate-bound $\mathrm{Cu}$ species. The $\mathrm{pH}$ of the $\mathrm{QR}$ residues was $<5$ when the $\mathrm{Cu}$ dose was $>27,500 \mathrm{mg} / \mathrm{L}$ (Table 3). This explains the high soluble $\mathrm{Cu}$ concentration in the $\mathrm{QR}$ residues at high $\mathrm{Cu}$ doses because the solubility of $\mathrm{Cu}$ compounds tend to increase with decreasing $\mathrm{pH}$. Since aluminium oxides are good adsorbents for $\mathrm{Cu}[31,32]$, the presence of substantial amounts of aluminium oxides/hydroxides (boehmite and gibbsite) might be responsible for the increased amounts of adsorbed $\mathrm{Cu}$ and consequently contributed significantly to the high proportion of Fraction I-Cu species in QR. The Fraction II-dominated regime for $\mathrm{Cu}$ in GR was attributable to the presence of considerable amounts of atacamite [22]. Fraction I-Cu species was believed to be more labile than Fraction II-Cu species [29]. Therefore, it appears that the water-borne $\mathrm{Cu}$ was more tightly bound by GR than QR. This suggests that the former is a better material than the latter in terms of its capacity to immobilize water-borne $\mathrm{Cu}$ and maintain long-term stability of the immobilized $\mathrm{Cu}$ species.

The $\mathrm{Cu}$ scavenging capacity of GR was over $247 \mathrm{~g} / \mathrm{kg}$, which was much greater than that reported for an alginate encapsulated magnetic sorbent $(63 \mathrm{~g} / \mathrm{kg})$ [33] and other organic sorbents $(3.9-16.4 \mathrm{~g} / \mathrm{kg})[34,35]$. The extremely high capacity of GR to immobilize water-borne $\mathrm{Cu}$ was attributable to the precipitation of atacamite as a result of acid neutralization by the alkaline materials present in the red mud. This differs from the adsorption mechanisms dominated in the latter scenarios. It is possible that adsorption mechanisms were also involved in our experiment. However, the adsorption fingerprints in the $\mathrm{Cu}$ dose-response chart could be masked by the strong precipitation footprints.

Copper is commonly present in wastewater generated by mining, printed circuit board manufacturing, electronics plating, plating, wire drawing, copper polishing, paint manufacturing, wood preservatives and printing operations. The research findings obtained from this study have implications for developing innovative technologies to treat various $\mathrm{Cu}$-containing wastewaters.

\section{Conclusions}

The highly basic, $\mathrm{CaCO}_{3}$-rich red mud had much stronger capacity than the seawater-neutralized, boehmite-dominated red mud in terms of scavenging $\mathrm{Cu}$ from solutions. It is also likely that the $\mathrm{Cu}$ 
was more tightly retained by the former than the latter. Based on these observations, it is concluded that the heterogeneity of red mud has marked influences on its capacity to immobilize water-borne $\mathrm{Cu}$ and maintain the long-term stability of the immobilized $\mathrm{Cu}$ species.

\section{Acknowledgments}

This work was financially supported by the Natural Science Foundation of China (Project No. 40471067 and 40773058) and the Guangdong Bureau of Science and Technology (Project No. 2005A30402006).

\section{References}

1. Knight, J.C.; Wagh, A.S.; Reid, W.A. The mechanical properties of ceramics from bauxite waste. J. Mater. Sci. 1986, 21, 2179-2184.

2. Lopez, E.; Soto, B.; Arias, M.; Nunez A.; Rubinos, D.; Barral, T. Adsorbent properties of red mud and its use for wastewater treatment. Water Res. 1998, 32, 1314-1322.

3. Lin, C.; Long, X.; Mai, S.; Xu, S.; Chu, C.; Jiang, D. Effects of multi-conditioners on minesite acid sulfate soils for vetiver grass growth. Pedosphere 2004, 14, 371-378.

4. Snars, K.E.; Gilkes, R.J.; Wong, M.T.F. The liming effect of bauxite processing residue (red mud) on sandy soils. Aust. J. Soil Res. 2004, 42, 321-328.

5. Maddocks, G.; Lin, C.; McConchie, D. Effect of bauxsol and biosolids on soil conditions of acid-generating mine spoil for plant growth. Environ. Pollut. 2004, 127, 157-167.

6. Wang, S.; Boyjoo, Y.; Choueib, A.; Zhu, Z.H. Removal of dyes from aqueous solution using fly ash and red mud. Water Res. 2005, 39, 129-138.

7. Jústiz-Smith, N.; Buchanan, V.E.; Oliver, G. The potential application of red mud in the production of castings. Mat. Sci. Eng. A 2006, 420, 250-253.

8. Ghosh, I.; Guha, S.; Balasubramaniam, R.; Ramesh Kumar, A.V. Leaching of metals from fresh and sintered red mud. J. Hazard. Mater. 2011, 185, 662-668.

9. Zhang, N.; Liu, X.M.; Sun, H.H.; Li, L.T. Evaluation of blends bauxite-calcination-method red mud with other industrial wastes as a cementitious material: Properties and hydration characteristics. J. Hazard. Mater. 2011, 185, 329-335.

10. Qin, S.; Wu, B.L. Effect of self-glazing on reducing the radioactivity levels of red mud based ceramic materials. J. Hazard. Mater. 2011, 198, 269-274.

11. Liu, D.Y.; Wu, C.S. Stockpiling and comprehensive utilization of red mud research progress. Materials 2012, 5, 1232-1246.

12. Apak, R.; Tutem, E.; Hungal, M.; Hizal, J. Heavy metals cation retention by unconventional sorbents (Red mud and fly ashes). Water Res. 1998, 32, 430-440.

13. Pradhan, J.; Das, S.N.; Thakur, R.S. Adsorption of hexavalent chromium from aqueous solution by using activated red mud. J. Colloid Interface Sci. 1999, 217, 137-141.

14. Lombi, E.; Zhao, F.J.; Zhang, G.; Sun, B.; Fitz, W.; Zhang, H.; McGrath, S.P. In situ fixation of metals in soils using bauxite residue: chemical assessment. Environ. Pollut. 2002, 118, 435-443.

15. Ciccu, R.; Ghiani, M.; Serci, A.; Fadda, S.; Peretti, R.; Zucca, A. Heavy metal immobilization in the mining-contaminated soils using various industrial wastes. Miner. Eng. 2003, 16, 187-192. 
16. Friesl, W.; Horak, O.; Wenzel, W.W. Immobilization of heavy metals in soils by the application of bauxite residues: Pot experiments under field conditions. J. Plant Nutr. Soil Sci. 2003, 166, 191-196.

17. Lin, C.; Maddocks, G.; Lin, J.; Lancaster, G.; Chu, C. Acid neutralizing capacity of two bauxite residues and their potential applications for treating acid sulfate soil and water. Aust. J. Soil Res. 2004, 42, 649-657.

18. Dan, U. Chromate removal from water using red mud and cross flow microfiltration. Desalination 2005, 181, 135-143.

19. Castaldi, P.; Melis, P. Evaluation of the interaction mechanisms between red muds and heavy metals. J. Hazard. Mater. 2006, 136, 324-329.

20. Liu, Y.; Lin, C.; Wu, Y. Characterization of red mud derived from a combined bayer process and bauxite calcination method. J. Hazard. Mater. 2007, 146, 255-261.

21. Wang, S.; Ang, H.M.; Tadé, M.O. Novel applications of red mud as coagulant, adsorbent and catalyst for environmentally benign processes. Chemosphere 2008, 72, 1621-1635.

22. Ma, Y.Q.; Lin, C.X.; Jiang, Y.H.; Lu, W.Z.; Si, C.H.; Liu, Y. Competitive removal of water-borne copper, zinc and cadmium by a $\mathrm{CaCO}_{3}$-dominated red mud. J. Hazard. Mater. 2009, 172, 1288-1296.

23. Smiljanić, S.; Smičiklas, I.; Perić-Grujić, A.; Šljivić, M.; Đukić, B.; Lončar, B. Study of factors affecting $\mathrm{Ni}^{2+}$ immobilization efficiency by temperature activated red mud. Chem. Eng. J. 2011, $168,610-619$.

24. Luo, H.L.; Huang, S.S.; Luo, L.; Wu, G.Y.; Liu, Y. Modified granulation of red mud by weak gelling and its application to stabilization of $\mathrm{Pb}$. J. Hazard. Mater. 2012, 227-228, 265-273.

25. Liu, W.C.; Yang, J.K.; Xiao, B. Review on treatment and utilization of bauxite residues in China. Int. J. Miner. Process. 2009, 93, 220-231.

26. Gräfe, M.; Power, G.; Klauber, C. Bauxite residue issues: III. Alkalinity and associated chemistry. Hydrometallurgy 2011, 108, 60-79.

27. Gu, S.; Yin, Z.; Yang, Z.; He, W. Improvements of the Processes to Produce Alumina from Chinese Diaspore Bauxite. In Light Metals; Crepeau, P.N., Ed.; The Minerals, Metals \& Materials Society: Warrendale, PA, USA, 2003; pp. 153-158.

28. McAuthur, L.; Greensill, C. Mineralogical Analysis of Weipa Bauxite Using NIR Spectroscopy. In Proceedings of Australian Institute of Physics 17th National Congress, Brisbane, Australia, 3-8 December 2006; Australian Institute of Physics: South Melbourne, Australia, 2006; pp. 3-8.

29. Sahuquillo, A.; Lopez-Sanchez, J.F.; Rauret, G.; Ure, A.M.; Muntau, H. Sequential Extraction Procedures for Sediment Analysis. In Methodologies for Soil and Sediment Fractionation Studies; Quevauviller, P., Ed.; The Royal Society of Chemistry: Cambridge, UK, 2002; pp. 10-27.

30. Compton, R.G.; Pritchard, K.L. The dissolution of calcite at $\mathrm{pH}>7$ : Kinetics and mechanism. Philos. Trans. R. Soc. London, Ser. A 1990, 330, 47-70.

31. Bibak, A. Cobalt, copper, and manganese adsorption by aluminium and iron oxides and humic acid. Commun. Soil Sci. Plan. 1994, 25, 19-20.

32. Silveira, M.L.A.; Alleoni, L.R.F. Copper adsorption in tropical oxisols. Braz. Arch. Biol. Technol. 2003, 46, 529-536.

33. Lim, S.F.; Zheng, Y.M.; Zou, S.W.; Chen, J.P. Characterization of copper adsorption onto an alginate encapsulated magnetic sorbent by a combined FT-IR, XPS, and mathematical modeling study. Environ. Sci. Technol. 2008, 42, 2551-2556. 
34. Ho, Y.S.; Wase, D.A.J.; Forster, C.F. The adsorption of divalent copper ions from aqueous solution by sphagnum moss peat. Trans. IChemE 1994, 72, 185-194.

35. Tumin, N.D.; Chuah, A.L.; Zawani, Z.; Rashid, S.A. Adsorption of copper from aqueous solution by Elais guineensis kernel activated carbon. J. Eng. Sci. Technol. 2008, 3, 180-189.

(C) 2012 by the authors; licensee MDPI, Basel, Switzerland. This article is an open access article distributed under the terms and conditions of the Creative Commons Attribution license (http://creativecommons.org/licenses/by/3.0/). 